\title{
A New Schedule Estimation Technique for Construction Projects
}

\author{
Roger D. H. Warburton \\ Department of \\ Administrative Sciences, \\ Metropolitan College \\ Boston, MA 02215 \\ http://people.bu.edu/rwarb
}

DOI 10.5592/otmcj.2014.3.1

\section{Research paper}

\section{Keywords}

Schedule estimation, Schedule performance index, Earned schedule, Construction labor profile
ALLEN STUDIED HUNDREDS OF CONSTRUCTION PROJECTS AND DEVELOPED AN ACCU-RATE, PRACTICALLY USEFUL MODEL OF THEIR LABOR PROFILES. We combine Al-len's labor profile with standard Earned Value Management (EVM) techniques and derive a simple, practical formula that estimates the fi-nal schedule from early project data. The schedule estimation formula is exact; it requires no approximations. The estimate is also surprisingly accurate and available early enough in the project for the project manager to be able to take appropriate actions. We use one of Allen's real-world construction data sets to calibrate and validate our theoreti-cal model. Early estimates of the final schedule are remarkably accu-rate, and available early enough to be used to effect management changes. We also explain why a current schedule estimation method, Earned Schedule (ES), has a poor theoretical foundation and show that our model is superior to ES in predicting construction schedule delays. The model should provide warning of schedule delays early enough for project managers to take corrective actions. 


\section{INTRODUCTION}

Earned Value Management (EVM) has been successful in providing project manag-ers with early warning signals of project trouble and such signals were found to be re-liable as early as $15 \%$ into a project (Christensen 1993, Christensen \& Templin 2002). The Practice Standard for EVM (PMI 2005) defines the basic elements and suggests that EVM can play a crucial role in estimating costs (Christensen 1993, Christensen \& Templin 2002).

Historically, before it was re-engineered as Earned Value Management, the ideas were part of the Program Evaluation and Review (PERT) technique and later became the Cost and Schedule Control Systems (CSSC) tool (Fleming and Koppelman 1999). However, the application of EVM to schedule determination is problematic because the key schedule indicator, the schedule performance index (SPI), is time-dependent (Kerzner 2006, Lipke 2003). Therefore, while the SPI indicates a delay, it cannot be used to predict the length of a schedule delay (Meredith \& Mantel Jr. 2011). Three schedule forecasting methods have emerged to address this deficiency: Planned Value (Anbari 2003), Earned Duration (Jacob 2003), and Earned Schedule (Lipke 2003). There is statistical support for the idea that all methods seem to work in practice (Vanhoucke \& Vandevoorde 2007, Vanhoucke \& Vandevoorde 2006, Lipke, Zwikael \& Anbari 2009). However, all schedule estimation formulae appear to be based on a constant labor rate, so that the cumulative labor profile is linear in time.

Why should a model based on linear cumulative profiles for planned and earned value apply to projects whose labor curves are S-shaped? One can consider a linear profile to be an approximation of an actual S-curve.

What is needed is a simple and effective method for estimating a project's final schedule that is based on a sound theoretical model that has been calibrated by real-world data. In this paper, we provide such a theory for schedule estimation for the construction industry. The objective is to provide a formally grounded theory and to derive a reliable, practical schedule estimation method.

We begin by characterizing the labor rate curve proposed for the construction in-dustry by Allen (1979). We develop an equation that describes Allen's labor rate curve, as well as the corresponding cumulative labor $\mathrm{S}$-curve. From early project data, we derive the theoretical formula that allows us to accurately estimate the actual final schedule.

The expression for the schedule is straight forward and exact. It requires no ap-proximations and so the errors in the final schedule estimate should be solely due to the degree to which the project data follows the proposed labor rate profile.

Allen used hundreds of real-world data sets to calibrate his profile and demon-strated that it provides a remarkably accurate description of construction projects. One of Allen's examples concerns a project planned to be completed in 20 weeks, but that actually took 40 weeks. From that Allen data set, we obtain a surprisingly accurate estimate of the final schedule that can be made quite early in the project, a result that adds practical credibility to the theory. We conclude with a discussion of the wid-er project management implications.

\section{Literature}

Earned Value Management (EVM) is designed to measure a project's actual progress against its plan (Fleming \& Koppelman 2005). There are many metrics that work well in the forecast of a project's final cost (Christensen 1993). However, there are significant issues when using EVM to estimate the schedule (Lipke 2003, Lipke et al. 2009, Meredith \& Mantel Jr. 2011).
Three methods have been proposed to address this shortcoming in schedule estimation: Planned Value, Earned Duration, and Earned Schedule.

The Planned Value method calculates a planned value rate as PVRate $=\mathrm{BAC} /$ PD (Anbari 2003). This method uses averages, and so its predictions will be accurate to the extent that the averages represent actual, time-dependent quantities. In the Earned Duration method the performance needed to finish within the planned duration is represented by a quantity denoted as the To-Complete SPI, TCSPI (Jacob 2003). For each time unit spent on the remaining work, TCSPI time units are required to be earned in order to finish according to the plan.

Lipke (2003) defined earned schedule (ES) with a phenomenological construction and explained it further in his book (Lipke 2010). Stratton (2007) provided one of the first formal definitions for ES, which is illustrated in Figure 3. The ES method has been shown to outperform other forecasting methods (Vanhoucke \& Vandevoorde 2007, Vanhoucke \& Vandevoorde 2006).

Jacob \& Kane (2004) argued that EVM can only be used to measure performance when SPI metrics are used at the activity level, and not at higher WBS levels. Their simple example leads to misleading results, because delayed activities that are not on the critical path should not contribute to schedule metrics.

According to Vanhoucke \& Vandevoorde (2006), all forecasting methods yield similar results. This has also been observed by Jacob \& Kane (2004), who attribute the high correlation of all methods to the fact that they apply the same basic parameters. More importantly, and somewhat underappreciated, is that the theory of all methods is based on the linearity of the cumulative labor profile. Unfortunately, most projects seem to follow a non-linear, S-shaped, cumulative labor curve and, so, the linearity as-sumption makes the accuracy of the schedule 
prediction formulae questionable, at least from a theoretical perspective. Recently, Lipke et al. (2009) studied 12 projects and estimates of the final cost and the duration were claimed to be sufficiently relia-ble for general application of the ES forecasting method. While the statistical support is conclusive, no theoretical underpinning for ES was provided and, so, we are left with the question of precisely where the model is applicable.

In general, the validity of S-curves in construction was established by Christian \& Kallouris (1991). Allen formalized the shape of the S-curve by proposing that a trap-ezoidal histogram accurately describes the labor rate on construction contracts (Allen 1994) and applies to entire projects, sub-contracts, and even individual trade work.

Using labor profiles has proved successful for estimating and tracking projects in other industries. Cioffi (2006a) showed how a labor profile curve often used in popu-lation dynamics can be applied to project $\mathrm{S}$-curves, and gave a fascinating example of its application to the development of the Oxford English Dictionary, a project span-ning many decades (Cioffi 2006b).

One of the first theoretical models for including time dependence into EVM was proposed by Warburton (2011), who derived time-dependent expressions for the planned value, earned value, and actual cost, along with the cost and schedule per-formance indices. The model was built on the well-established Putnam-Norden-Rayleigh (PNR) labor rate profile and accurately predicted both the cost and the schedule early in the project. Warburton also applied the model to a well-known software data set, estimating the project's final cost and schedule from early project data, which converged faster to the correct answer with less variability than the standard Estimate-at-Completion (EAC) formula.

\section{ALLEN'S CONSTRUCTION LABOR RATE PROFILE}

Allen's management perspective is supported by the fact that on "well run" con-struction projects, the labor rate profile arises from management applying resources at the appropriate time. The first stage of the project is a linear build up from zero as work becomes progressively more available. Planning, ordering materials and under-standing of the local conditions requires fewer, but critical, people and more supervi-sion. These key people recruit local crews as more tasks become available to work on. In the second stage, which is about $50 \%$ through the schedule, a constant level of ef-fort is reached where conditions are optimal. Too many crews would over-crowd the area, while too few would reduce productivity. In stage three, the labor is gradually reduced as crews run out of work.

Allen validated his labor profile on a wide range of projects and subcontractor efforts. In one particularly impressive analysis, Allen summarized the S-curves for 40 different electrical contractors on 54 building projects in 32 cities. Remarkably, the en-tire variation in their time-scales is less than $10 \%$. The inescapable conclusion is that Allen's profile is an excellent fit to a wide variety of construction project data.

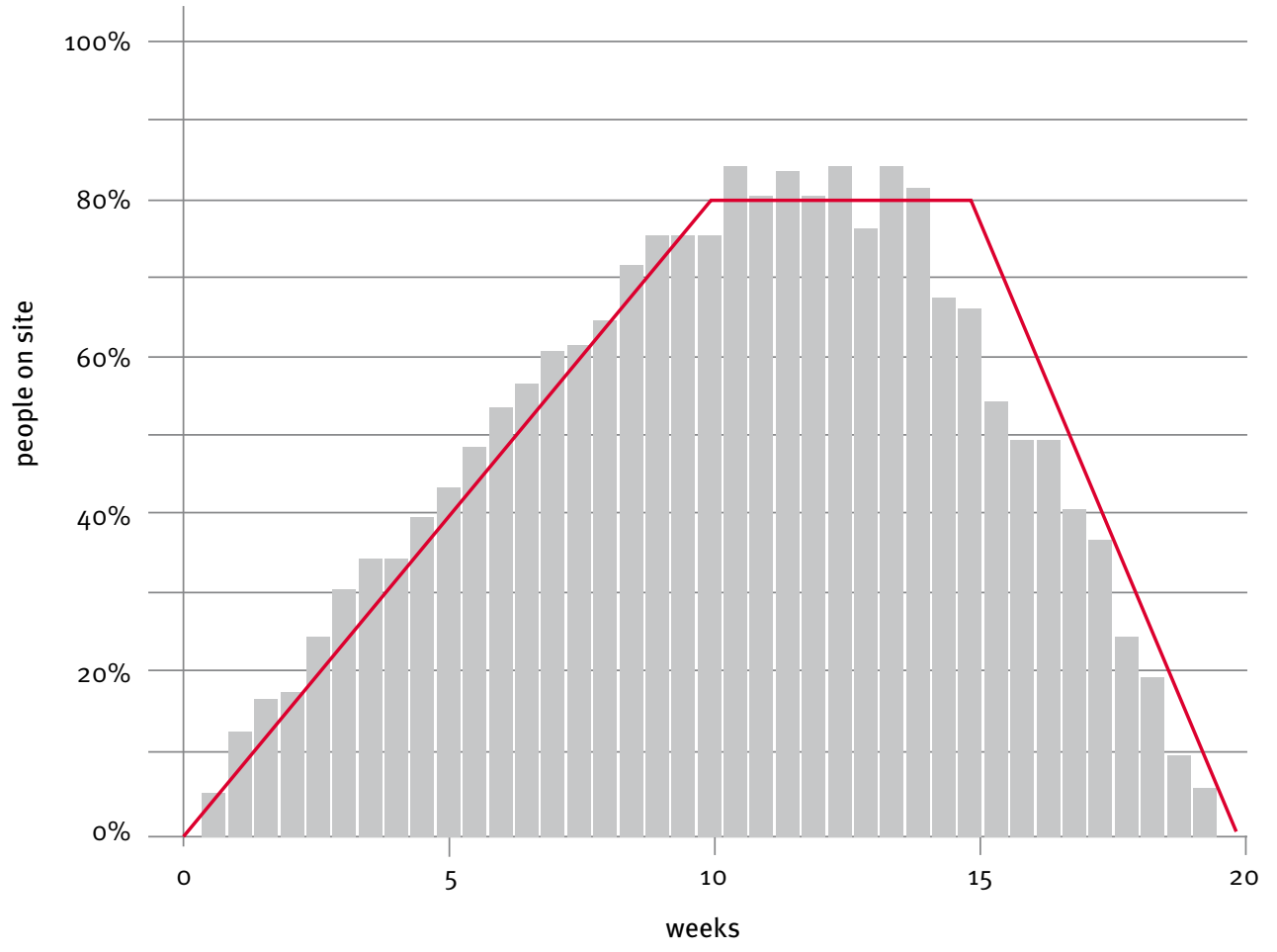

Figure 1:

Allen's construction
project data and the
associated trapezoidal
labor rate profile.

Allen's construction associated trapezoidal 
Allen's labor rate profile for a particular construction project is shown in Figure 1. The vertical bars show the actual number of workers on site each week. The actual la-bor rate can be accurately represented by a trapezoid. In the first phase, the labor increases linearly to a peak, which occurs about half way through the project. The la-bor remains constant at this peak value until the $75 \%$ completion point. The labor is then reduced linearly to zero at the end of the project.

Since the trapezoidal labor rate profile displays the actual number of people on site, it is directly proportional to the actual labor cost, ac(t). We use lower case letters to indicate instantaneous (weekly) quantities, while capital letters are used for cumula-tive quantities.

The end of the project is denoted as Te. The linear ramp up spans $50 \%$ of the schedule, [0, Te/2]. The second stage lasts from $50 \%$ to $75 \%$ of the project, $[\mathrm{Te} / 2,3 \mathrm{Te} / 4]$. In the third stage, the labor rate is reduced linearly to zero, $[3 \mathrm{Te} / 4, \mathrm{Te}$ ]. The peak value of the labor rate curve is at the value, $\mathrm{Pa}$. Thus, the equation for the trape-zoidal actual labor rate profile, applicable to construction, is:

$$
\operatorname{ac}(\mathrm{t})=\left\{\begin{array}{cc|}
\frac{2 \mathrm{~Pa}}{\mathrm{Te}} \mathrm{t} & \mathrm{o}<\mathrm{t}<\mathrm{Te} / 2 \\
\mathrm{~Pa} & \frac{\mathrm{Te}}{2}<\mathrm{t}<3 \mathrm{Te} / 4 \\
4 \mathrm{~Pa}\left(1-\frac{\mathrm{t}}{\mathrm{Te}}\right) & \frac{3 \mathrm{Te}}{4}<\mathrm{t}<\mathrm{Te} .
\end{array}\right.
$$

This equation is plotted in Figure 1 , where it can be seen that the agreement be-tween theory and practice is excellent. Allen had access to hundreds of real-world da-ta sets, which establishes (1) as an accurate description of construction projects.

\section{Construction EVM}

In EVM parlance, the weekly rate at which activities are planned to be completed is called the planned value, pv(t). Following Allen, we assume that the planned labor rate also has a trapezoidal shape, an assumption that is well verified by Allen's data sets. The planned completion time for the project is Tp and the peak in the planned la-bor rate curve is denoted as $\mathrm{Pp}$. Therefore, the expression for the planned value, $\mathrm{pv}(\mathrm{t})$, has the same form as (1) with $\mathrm{Pp}$ replacing $\mathrm{Pa}$ and $\mathrm{Tp}$ replacing $\mathrm{Te}$. The weekly planned value, $\mathrm{pv}(\mathrm{t})$, is plotted in Figure 2.

The cumulative Planned Value, PV (t), is defined as the cumulative sum of the weekly planned values, so:

$$
P V(t)=\int_{0}^{t} p v(t) d t .
$$

Eq. (2) generates a non-linear $\mathrm{S}$-curve. The cumulative planned value, PV (t), is plotted in Figure 3 and shows the typical S-curve.

The total labor, $\mathrm{L}$, is given by the area under the labor rate curve, which is easily calculated as the sum of the two triangles and the quadrilateral:

$$
\mathrm{L}=\frac{5}{8} \mathrm{PV} T \mathrm{e}^{\star}
$$

The total planned labor is the budget for the project, which is also given by the fi-nal value of the S-curve, i.e., PV (Te):

$$
L=P V(T e)=\left(\frac{5}{8}\right) P t e^{*}
$$

We can rearrange (4) as follows:

$$
\mathrm{P}=\frac{5}{8} \frac{\text { Total Labor }}{\mathrm{Te}}=1.6 \times \text { Average Labor. }
$$

This is Allen's Rule, which says that the Peak Labor is approximately 1.6 times the Average Labor. While it appears that Allen derived his rule from empirical observa-tion, we deduced it here as an inherent property of the trapezoidal labor rate profile.

We now derive an expression for the earned value. We assume that the project's actual execution does not necessarily follow its planned execution. The project was planned to end at $\mathrm{Tp}$, but it is delayed and ends at time, Te $>$ Tp. The key assumption is that while the earned value labor rate curve is delayed relative to the planned value labor rate curve, they both have a trapezoidal shape. The total planned labor equals the total earned value labor, so the earned value has a smaller value for the peak, which we denote as $\mathrm{Pe}$ <Pp. Therefore, the expression for the earned value, ev(t), has the same form as (2) with Pe replacing $\mathrm{Pp}$ and $\mathrm{Te}$ replacing $\mathrm{Tp}$.

Finally, we assume the actual labor is proportional to the earned value (as op-posed to the plan). This assumption is reasonable because earned value accumulates as deliverables are completed and it is reasonable to assume that the earned ex-penditures actually follow the deliverables. Therefore, we write: $\mathrm{ac}(\mathrm{t})=(1+\mathrm{c}) \mathrm{ev}(\mathrm{t})$, where $\mathrm{c}$ represents a cost overrun factor. In this paper, we are more interested in schedule than cost, so the cost formula is not particularly important in what follows, but it does allow us to complete the model, and in a reasonable and straightforward man-ner.

The weekly planned, earned and actual data are shown in Figure 2. 


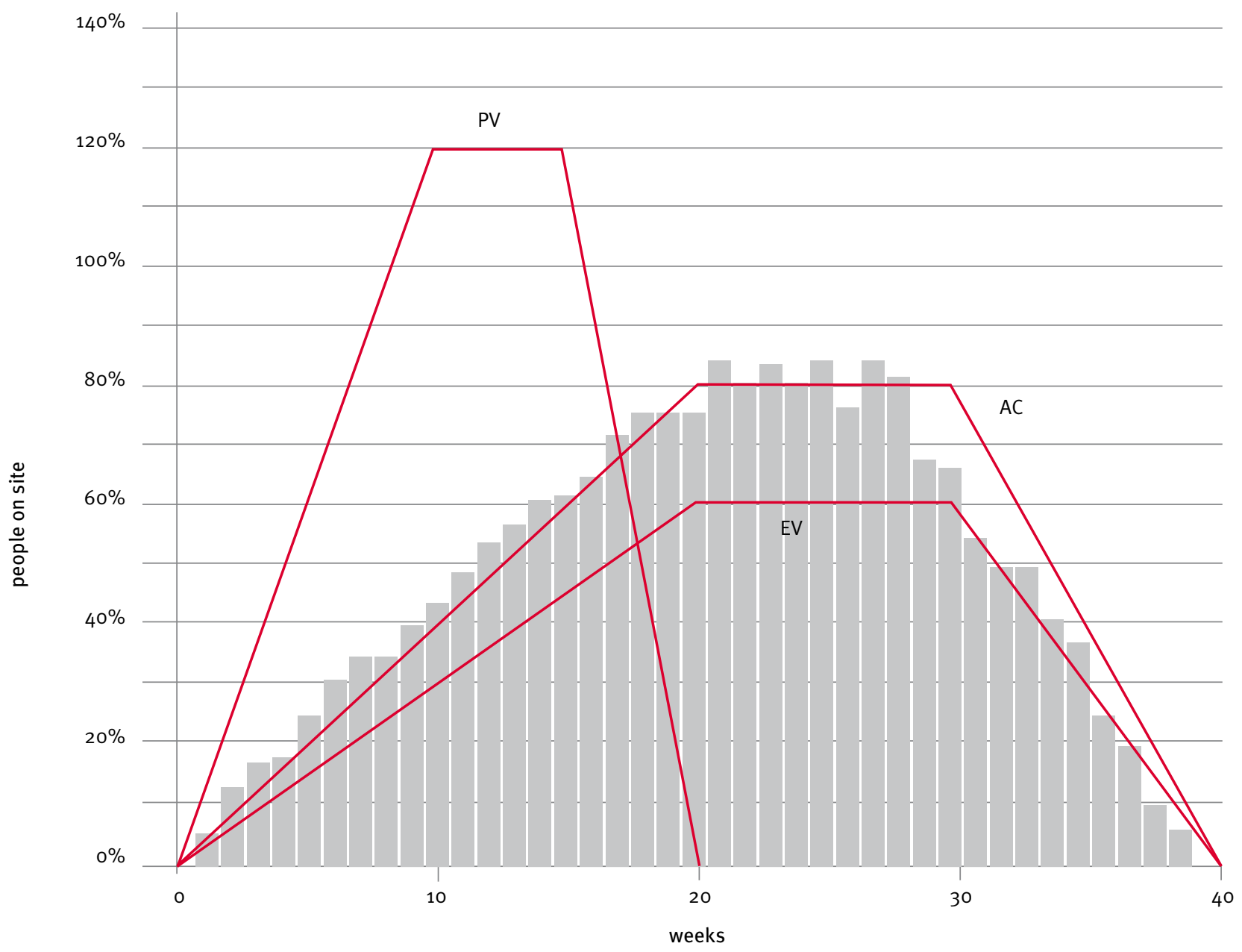

Figure 2 Weekly planned value, earned value, and actual cost for the construction labor profile.

Figure 3 Cumulative planned value, earned value, and actual cost for the construction labor profile. All three are non-linear S-curves.

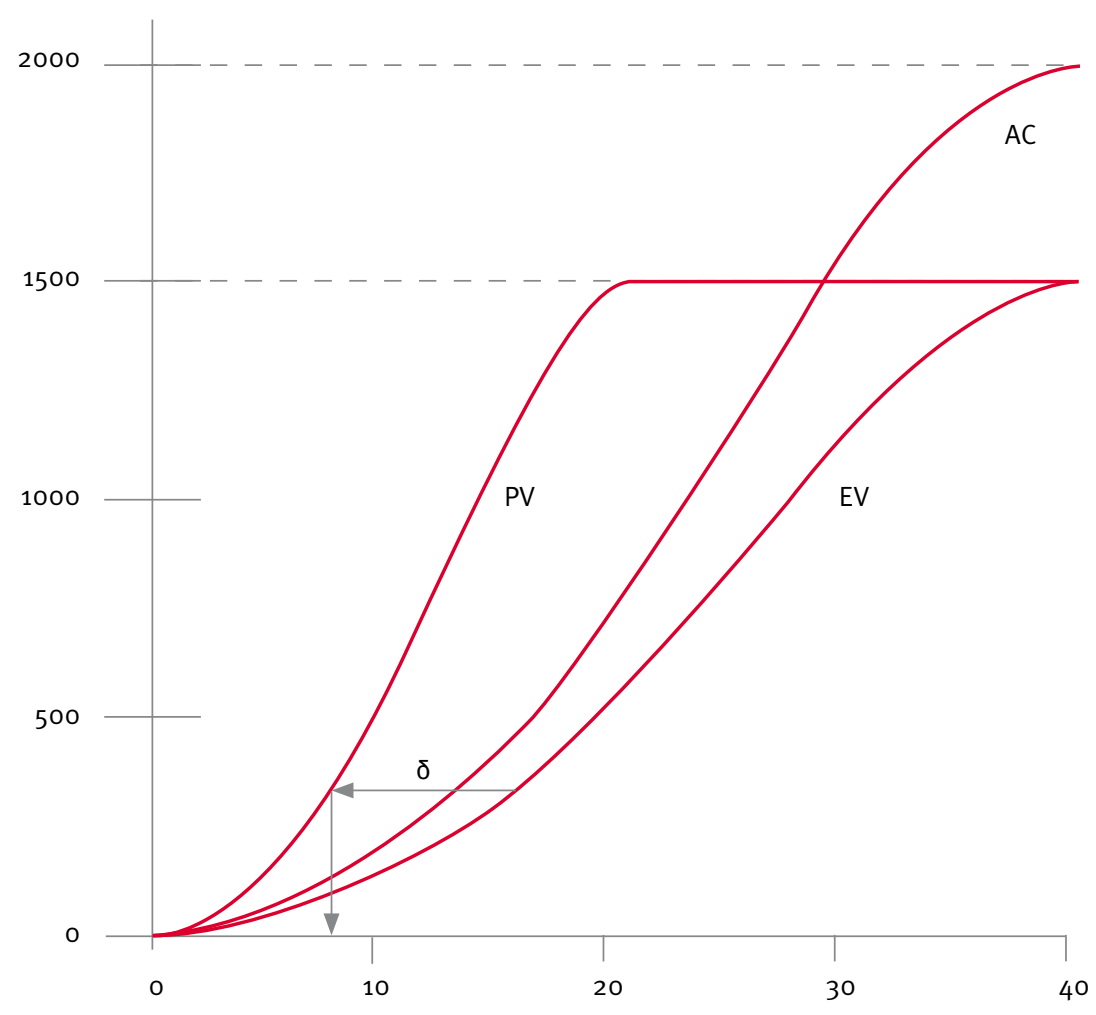




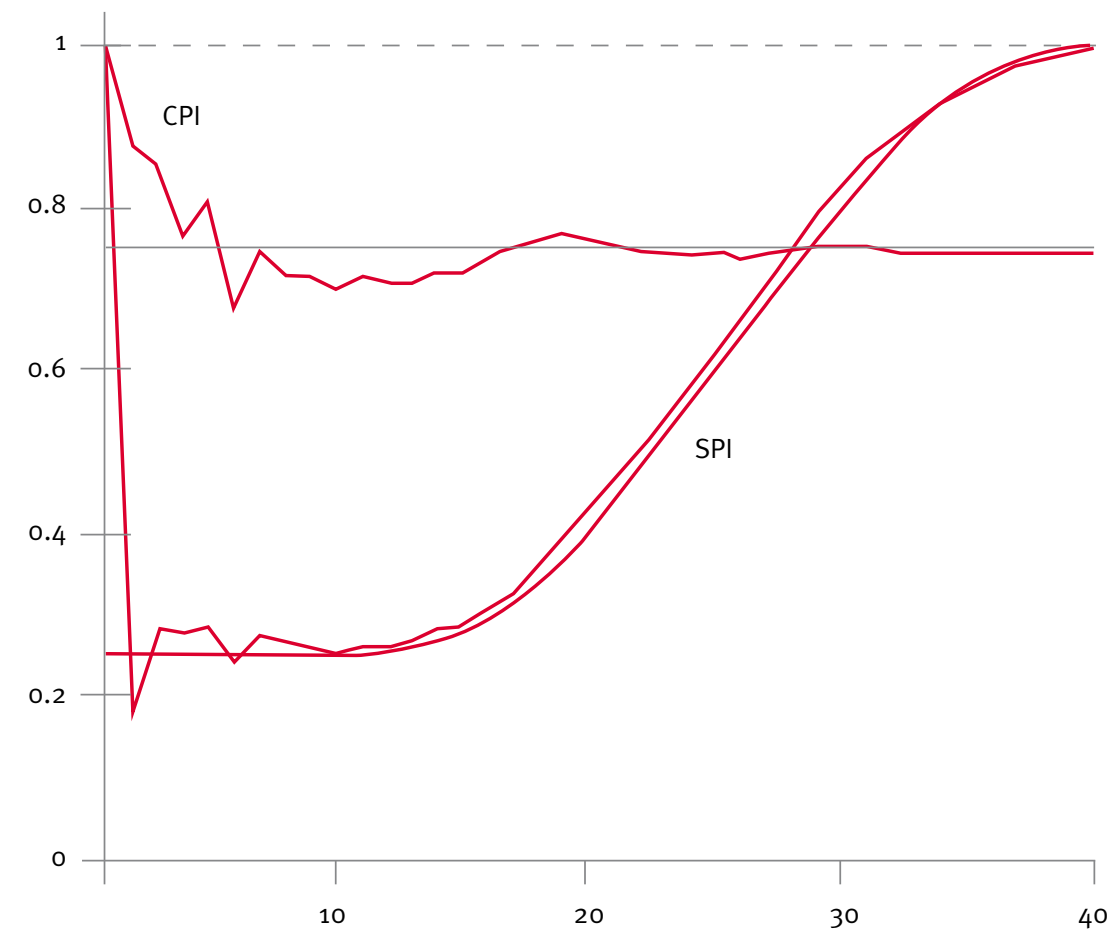

Figure ${ }_{4} \mathrm{CPI}(\mathrm{t})$ and $\mathrm{SPI}(\mathrm{t})$ for the construction project labor rate profile.

As it was for the planned value, the cumulative versions are defined as the sum of the weekly planned values, so:

$E V(t)=\int_{0}^{t} e v(s) d s \quad A C(t)=\int_{0}^{t} a c(s) d s$

These equations for the cumulative earned value and actual cost for the Allen pro-file are S-curves, and are shown in Figure 3. As a specific example, we have used the data from Figure 2. The project that was supposed to be complete after 20 weeks, but was delayed and, actually, finished after 40 weeks. There is a cost overrun, which is indicated by the $\mathrm{AC}(\mathrm{t})$ curve rising above the PV (t) curve.

\section{Estimating The Final Schedule}

In the previous section, we determined that the project was significantly delayed. It is of interest, therefore, to ask how early in the project could one detect the delay and at what point could one accurately estimate the new schedule?
Substituting for $\mathrm{Pp} / \mathrm{Pe}$ from (9) into (8), gives:

$$
S P I=\frac{T^{2} p}{T^{2} e}
$$

Therefore, the new estimate of the schedule is determined from:

$$
\mathrm{SPI}=\frac{\mathrm{T}^{2} \mathrm{p}}{\mathrm{T}^{2} \mathrm{e}} \quad \mathrm{Te}=\frac{\mathrm{Tp}}{\sqrt{\mathrm{SPI}}}
$$

Early in the project, where the linear expressions for the planned and earned val-ue labor rates are valid, the SPI is a constant. Therefore, if we measure the SPI early on, an estimate of the final schedule is available from (10).

Therefore, early in the project, a value can be determined for the SPI, and the fi-nal schedule can be accurately estimated. This is shown in Figure 5 , where (10) was used to estimate the final schedule. After only 4-5 weeks, the estimate of the final schedule is quite good and it shows that the schedule has doubled.

We emphasize that the estimate for the final schedule from (10) is exact, no ap-proximations were required. Eq. (10) only depends only on the assumption that the planned and earned value rates are described by trapezoidal functions. Even though the SPI is a function of time, the estimate in equation (10) is a constant because the time cancels from (8). The result then simply follows from the application of standard EVM definitions.
In the early phase of the project (up to $\mathrm{Te} / 2)$, the $\mathrm{PV}(\mathrm{t}), \mathrm{EV}(\mathrm{t})$ and $\mathrm{AC}(\mathrm{t})$ are given by:
$P V(t)=\frac{t}{2 T p} \quad E V(t)=\frac{t}{2 T e} \quad A C(t)=(1+c) E V(t)$

Therefore, the SPI and CPI are given by:

$$
\mathrm{SPI}=\frac{\mathrm{EV}(\mathrm{t})}{\mathrm{PV}(\mathrm{t})} \quad \mathrm{CPI}=\frac{\mathrm{EV}(\mathrm{t})}{\mathrm{AC}(\mathrm{t})}
$$

At the end of the project, all of the planned labor has been earned and, so, the total planned value equals the total earned value. Using (4) for the total labor gives:

$$
\mathrm{L}=\frac{5}{8} \mathrm{Pp} \mathrm{Tp}=\frac{5}{8} \mathrm{Pe} \mathrm{Te}
$$

\section{Comparison With Earned} Schedule

The Earned Schedule at time, $t$, is denoted as, ES(t), and is defined as the time of the intersection of the cumulative earned value curve at time, $t$, projected back to the planned value curve (Lipke 2010). This construction is shown in Figure 3. Mathematical-ly, the earned schedule intersection is defined as: $\mathrm{EV}(\mathrm{t})=\mathrm{P}(\mathrm{t}-\delta)$, where $\delta$ is defined as the schedule delay. In the early stages, EV ( $t)$ and $P V(t)$ are given by (7), so: 


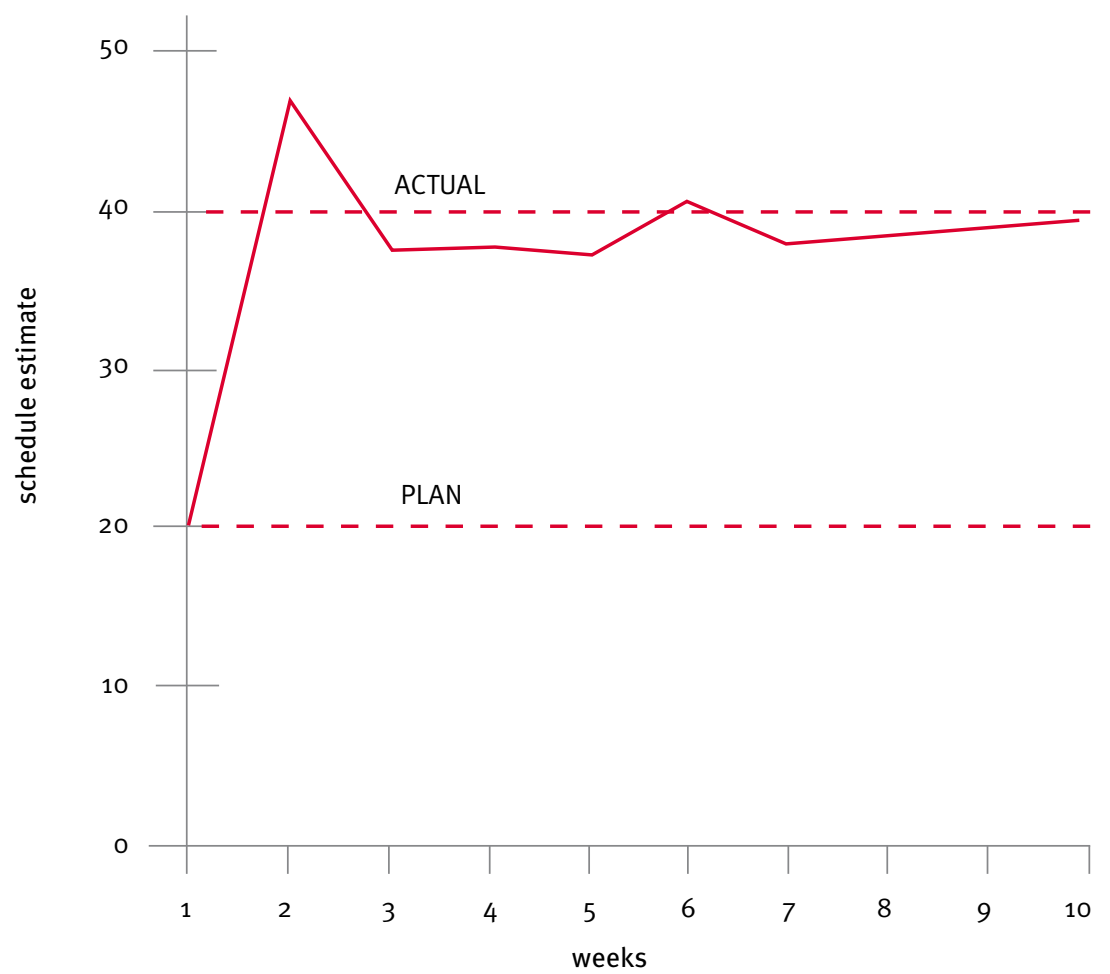

Figure 5 Early estimates of the final schedule.

$$
\delta(t)=t\left(1-\frac{T e}{T p}\right)
$$

Early on, the expression for $\delta(t)$ is a linear function of time. Since the earned schedule is $E S(t)=t-\delta(t)$, we have:

$$
E S(t)=t\left(\frac{T e}{T p}\right)
$$

The earned schedule is also a function of time. However, since this function is only good up in the linear region of the trapezoid ( $T p<10)$, we do not have an expression for $\mathrm{ES}(\mathrm{Tp})$, and, therefore, cannot determine Te.

Therefore, while there may be a statistical justification for using ES (Lipke et al. 2009), the above equations do not provide a theoretical justification to support its use. Therefore, from a theoretical perspective, we cannot conclude whether ES is valid when applied to construction projects.

to estimate the final schedule.

We compared our model to the earned schedule (ES) approach. construction case to estimate the final schedule.

The important conclusion is that we have a simple, exact expression for the sched-ule estimate for the construction labor profile, which is based on a sound theoretical model. Early in the project, we can estimate the final schedule using the standard SPI, which should lead to improved project planning and tracking.

\section{References}

Allen, W. (1979). “Developing the project plan.” Engineering Institute of Canada Annu-al Congress Workshop, Toronto, 3-9.

Allen, W. (1994). “A pragmatic approach to using resource loading, production and learning curves on construction projects." Canadian Journal of Civil Engineering 21, 939-953.

Anbari, Frank T. (2003). “Earned Value Project Management: Method and extensions." Project Management Journal 34(4), 12.

Christensen, D. S. (1993). "The estimate at completion problem: A review of three studies.” Project Management Journal 24(1), 37-42.

Christensen, D. S. \& C. Templin (2002). "EAC evaluation methods: Do they still work?” Acquisition Review Quarterly pp. 105-116.

Christian, J. \& G. Kallouris (1991). “An expert system for predicting the cost-time pro-files of building activities." Canadian Journal of Civil Engineering 18, 814 .

Cioffi, D. F. (2006a). “Subject expertise, management effectiveness, and the newness of a project: The creation of the Oxford English Dictionary.” Project Management Institute Research Conference, Montreal, Project Management Institute.

Cioffi, Denis F. (2006b). “Completing projects according to plans: An Earned-Value improvement index." Journal of the Operational Research Society 57, 290-295. While the growth in ES can be measured, there is no theoretical formula that relates it to the final sched-ule. Therefore, it cannot be used in the
Fleming, Q. W. \& J. M. Koppelman (2005). “Earned Value Project Management" 3rd edn, Project Management Institute, Newtown Square, PA.

Fleming, Q. W. \& J. M. Koppelman (1999). “The Earned Value Body of Knowledge” Seminar 
and Symposium, Project Management Institute, Newtown Square, PA, January.

Jacob, D.S. (2003). “Forecasting project schedule completion with earned value metrics." The Measurable News 1(11), 7-9.

Jacob, D.S. \& M. Kane (2004). “Forecasting schedule completion using earned value metrics revisited." The Measurable News 1(11).

Kerzner, H. (2006). Project Management: A Systems Approach to Planning, Scheduling, and Controlling, 9th ed., John Wiley \& Sons, New York, NY.

Lipke, W. (2003). "Schedule is different." The Measurable News 31-34.

Lipke, W. (2010). Earned Schedule, Lulu (R) Publishing, Lexington, $\mathrm{KY}$.

Lipke, W, O. Zwikael, Henderson K. \& F. Anbari (2009). "Prediction of project out-come. The application of statistical methods to Earned Value Management and Earned Schedule performance indexes', International Journal of Project Man-agement 27, 400-407.

Meredith, J. R. \& S. J. Mantel Jr. (2011). Project
Management: A Managerial Approach, 8th edn, John Wiley \& Sons.

PMI (2005), Practice Standard for Earned Value Management, Project Management Institute, Newtown Square, PA.

Stratton, Ray (2007). “Applying earned schedule analysis to EVM data for estimating completion date." AACE International Transactions pp. 41-45.

Vanhoucke, M. \& S. Vandevoorde (2006). “A comparison of different project duration forecasting methods using Earned Value metrics." International Journal of Pro-ject Management 24, 289-302.

Vanhoucke, M. \& S. Vandevoorde (2007). “A simulation and evaluation of Earned Value Metrics to forecast the project duration', Journal of the Operational Re-search Society $58,1361-1374$.

Warburton, R. D. H. (2011). "A time-dependent Earned Value model for software pro-jects." International Journal of Project Management 29, 1082-1090. 